\title{
Adhesion of tissue glues to different biological substrates
}

\author{
A.I. Bochyńska ${ }^{a, b}$, G. Hannink ${ }^{b}$, P. Buma ${ }^{b}$ and D.W. Grijpma ${ }^{a, c *}$
}

\begin{abstract}
Tissue adhesives are attractive materials with potential to replace the use of sutures and staples in the repair of the injured tissues. The research field of tissue adhesives is dynamically growing, and different methods and tissue models are employed to evaluate the adhesive properties of newly developed materials. It is thus difficult to directly compare the properties of materials developed by researchers from different groups. Moreover, the extrapolation of results obtained using different tissue models to the targeted human tissues is often not possible. Therefore, the purpose of the current study was to evaluate the adhesive properties of the three different tissues adhesives: the clinically used Dermabond ${ }^{\circledR}$ and fibrin glues, and the recently developed isocyanate-terminated three-armed adhesive block copolymers. Different biological substrates were used to assess their adhesion strengths: bovine Achilles tendon, meniscus tissue and skeletal muscle, chamois leather, and collagen films. Comparisons of the adhesive properties of the glues with these substrates were made. The obtained results were analyzed in terms of the chemistry and the adhesion mechanisms of the glues, and the composition and properties of the substrates like their hydrophilicity and surface morphology. We conclude that standardized procedures and models should be developed to allow direct comparison between the different (developed) tissue adhesives and to enable extrapolation of the results towards the targeted human tissues. Copyright $\odot 2016$ John Wiley \& Sons, Ltd.
\end{abstract}

Keywords: tissue adhesive; adhesion to biological substrates; tissue models; tissue repair

\section{INTRODUCTION}

Tissue adhesives are an attractive class of materials with the potential to be used as a replacement of other surgical techniques, such as sutures or staples. Tissue adhesives cause minimal tissue trauma, they are easy to apply, and there is no need to remove them after the tissue has healed. ${ }^{[1]}$ Therefore, much interest has recently been paid to the development of new adhesive materials, which are aimed at the repair of different types of tissues and injuries, e.g. skin lacerations, pulmonary leaks, abdominoplasty, cardiovascular vessels, meniscus tears, and bone fractures. $^{[2-6]}$

However, the availability of the human tissues for evaluating adhesive properties of newly developed adhesives is limited. Therefore, different materials have been employed in laboratory practice to serve as tissue models. Examples are polyamide films ${ }^{[7,8]}$ gelatin pieces, ${ }^{[9-11]}$ collagen membranes, ${ }^{[12]}$ animal tissues, and even models using pieces of wood and pig skin. ${ }^{[13]}$ However, the adhesion strength of the glues may significantly differ when tested using these tissue models instead of the targeted living tissues. Moreover, even though norms for testing adhesive materials exist, e.g. ASTM F2255-05, still, the variability in the preparation of the substrates, the gluing procedures, and the curing times can introduce large variations in the obtained results and direct comparison of the novel materials developed in different research groups is often not possible.

Therefore, the aim of this study was to evaluate and compare the adhesive strength of three different tissue glues with different biological substrates, using the clinically applied Dermabond $^{\circledR}$ and fibrin glue, and a recently developed novel three-armed adhesive block copolymer. The differences in the observed adhesive strengths are discussed in terms of the hydrophilicity of the substrates, their surface morphology, and the contact angle between applied glues and the surfaces. Recommendations towards choosing adequate substrates for evaluating adhesion strengths of newly developed glues are formulated.

\section{EXPERIMENTAL}

\section{Tissue adhesives}

Three tissue adhesives were used in this study: Dermabond ${ }^{\circledR}$ (Ethicon, Johnson and Johnson, the Netherlands), fibrin glue [mixture of fibrinogen $(100 \mathrm{mg} / \mathrm{mL})$ and thrombin $(100 \mathrm{U} / \mathrm{mL})$ in PBS, both isolated from bovine plasma, Sigma-Aldrich, the Netherlands] and a three-armed block copolymeric isocyanate-terminated adhesive, TMPE- $\left(\mathrm{TMC}_{2}-\mathrm{HDI}\right)_{3}$, which was synthesized as described in detail previously. ${ }^{[14]}$ The building

\footnotetext{
* Correspondence to: Prof. D.W. Grijpma, MIRA Institute for Biomedical Engineering and Technical Medicine and Faculty of Science and Technology, Department of Biomaterials Science and Technology, University of Twente, Enschede, the Netherlands.

E-mail: d.w.grijpma@utwente.nI

a A.I. Bochyńska, D.W. Grijpma

MIRA Institute for Biomedical Engineering and Technical Medicine and Faculty of Science and Technology, Department of Biomaterials Science and Technology, University of Twente, Enschede, the Netherlands

b A.I. Bochyńska, G. Hannink, P. Buma

Orthopaedic Research Laboratory, Department of Orthopaedics, Nijmegen Centre for Molecular Life Sciences, Radboud University Nijmegen Medical Centre, Nijmegen, the Netherlands

c D.W. Grijpma

W.J. Kolff Institute, Department of Biomedical Engineering, University Medical

Centre Groningen, University of Groningen, Groningen, the Netherlands
} 
blocks of the copolymer were trimethylolpropane ethoxylate (TMPE, $M_{n}=450 \mathrm{~g} / \mathrm{mol}$ ), trimethylene carbonate (TMC), and hexamethylene diisocyanate (HDI).

\section{Preparation of the substrates for gluing experiments}

Bovine meniscus, bovine Achilles tendon, and bovine skeletal muscle tissue were obtained from a local slaughterhouse. Meniscus tissue was cut with a cryotome (Microm GmbH, Germany) in the direction along the alignment of the collagen fibers to obtain strips measuring approximately $0.5 \times 10 \times 25 \mathrm{~mm}$. Achilles tendons were cut lengthwise in the same manner. Skeletal muscle tissue was frozen and then cut with a scalpel to strips of approximately $2 \times 10 \times 25 \mathrm{~mm}$. Chamois leather (dermal sheep collagen) was cut in strips of $1 \times 10 \times 25 \mathrm{~mm}$. Collagen films were prepared by swelling $1 \mathrm{w} / \mathrm{v} \%$ of type I insoluble collagen (from bovine Achilles tendon, Sigma Aldrich, Germany) in acetic acid (0.05 M) overnight at $4^{\circ} \mathrm{C}$. Subsequently, the mixture was shredded for $10 \mathrm{~min}$ at $9500 \mathrm{rpm}$ at $0^{\circ} \mathrm{C}$ using a Braun MR $500 \mathrm{HC}$ blender (Braun, Germany). The resulting slurry was filtered through a nylon filter (average pore size $100 \mu \mathrm{m}$ ), and it was cast on a glass plate using a 3-mm thick casting knife and then left to dry under fume hood at room temperature. After drying, collagen films of a thickness of approximately $100 \mu \mathrm{m}$ were obtained. Because of their weak mechanical properties, they were mounted on steel plates of a size $0.5 \times 10 \times 30 \mathrm{~mm}$ with a cyanoacrylate glue prior to adhesion testing. All substrates were kept in water before use.

\section{Application of the tissue adhesives and evaluation of their bonding strength}

All tissues were thawed and together with chamois leather, and collagen films were kept in demi water to prevent drying. The surfaces of the substrates were blotted dry, and the different tissue adhesives were applied onto the strips. Dermabond ${ }^{\circledR}$ was used as received. Fibrin glue was prepared by mixing two solutions (fibrinogen and thrombin) in a double syringe equipped with a static mixer (Sulzer, Switzerland) and directly applied onto the substrates. The three-armed copolymeric adhesive was applied using a spatula. In all cases, the adhesives covered an area of approximately $100 \mathrm{~mm}^{2}$. Two of these strips were then pressed together, immersed in water and left overnight at room temperature to allow attachment of the adhesives to the substrates and curing.

To determine the strength of the adhesive bonding of the glues to the substrates after curing, the wet specimens were subjected to lap shear adhesion testing using a Zwick Z020 universal tensile machine according to ASTM F2255-05 standard $(n=5)$. The grip to grip separation was $22 \mathrm{~mm}$, and the crosshead speed was $50 \mathrm{~mm} / \mathrm{min}$. The shear adhesive bond strength (S) was calculated as the maximum shear force divided by the glued area.

\section{Contact angle measurements}

Static contact angle measurement between different tissue adhesives and substrates were measured using optical contact angle device (OCA15, Dataphysics, Germany). The drop of adhesive was deposited onto the surface of the wet substrates, after which the drop contour was fitted by the Young-Laplace method. Each measurement was performed in triplicate.

\section{Determination of the water content of the substrates}

All tissues were thawed and together with chamois leather and collagen films were kept in demi water to prevent drying. Subsequently, the substrates $(n=3)$ were blotted dry and their initial mass was determined $\left(\mathrm{m}_{\mathrm{i}}\right)$. The samples were frozen in liquid nitrogen, freeze-dried, and their mass in the dry state was again determined $\left(m_{d}\right)$.

The water content of the substrates, expressed as a weight \%, was calculated as follows:

$$
W C=\frac{m_{i}-m_{d}}{m_{i}} \times 100 \%
$$

\section{Surface morphology of the substrates}

The surfaces of the substrates and the surfaces to which the glues were applied were visualized using scanning electron microscopy (SEM, $n=1$ ). The adhesives were applied on strips of the different substrates and then kept in water overnight to let the adhesives attach and cure. Subsequently, the samples were mounted on the SEM holders and were dried in an oven with convective air flow at $40^{\circ} \mathrm{C}$. The surfaces of the samples were gold-sputtered for $60 \mathrm{~s}$. The morphology was studied using Zeiss Gemini Sigma 300 SEM operating at $10 \mathrm{kV}$ electron beam. Crosssections of chamois leather and meniscus tissue were also imaged after application of the three-armed adhesive. These samples were prepared as described previously, but they were fractured in liquid nitrogen before drying. An FEI ESEM XL30 apparatus operating at $5 \mathrm{kV}$ electron beam was used in this case.

\section{RESULTS}

The adhesive strength of the glues to the different substrates was determined in the lap shear adhesion tests. The observed failure mechanism was in all cases adhesive failure: the glues detached from the substrates. The values of the adhesive strengths of particular glues were highly dependent on the type of the glued substrate (Fig. 1). The adhesion strength of Dermabond ${ }^{\circledR}$ varied from $20 \pm 6$ up to $869 \pm 373 \mathrm{kPa}$ for muscle tissue and collagen films, respectively. Fibrin glue had adhesive strengths

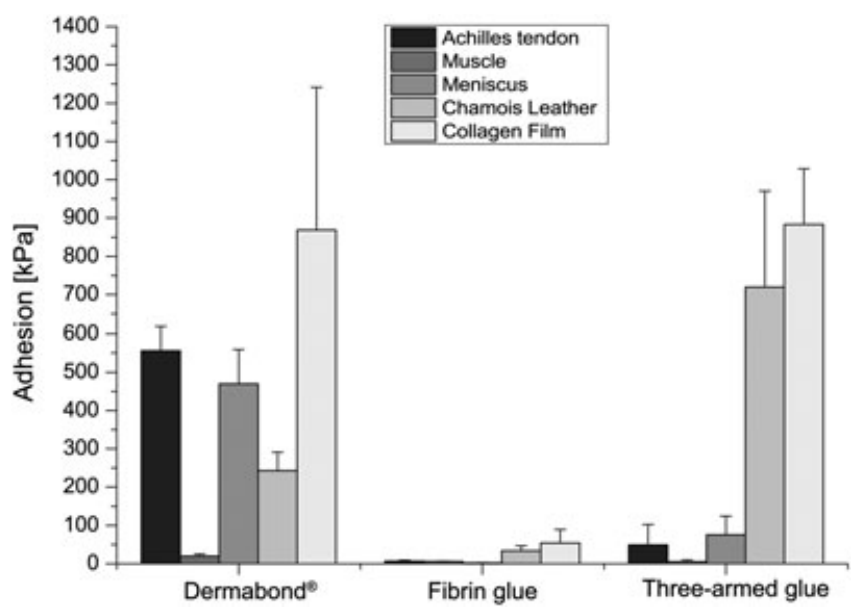

Figure 1. Adhesive strength of the different glues to different biological substrates determined in lap-shear testing. Data are presented as mean \pm standard deviations. 
ranging from $2 \pm 1$ to meniscus up to $54 \pm 35 \mathrm{kPa}$ to collagen films. The three-armed block copolymeric glue had the highest adhesive strength to chamois leather $(719 \pm 225 \mathrm{kPa})$ and collagen films $(883 \pm 118 \mathrm{kPa})$ and the lowest to muscle tissue $(5.3 \pm 4.3 \mathrm{kPa})$.

The static contact angles between drops of the glues and particular substrates are presented in Fig. 2. Contact angles between Dermabond $^{\circledR}$ and different substrates varied from $17.5 \pm 5.8^{\circ}$ to collagen films up to $35.8 \pm 2.1^{\circ}$ to muscle tissue. The contact angle between Dermabond ${ }^{\circledR}$ and chamois leather could not be determined, as drops of the glue were directly absorbed into the surface of the substrate. The contact angle between fibrin glue and muscle tissue and chamois leather was relatively low; $11.1 \pm 2.1^{\circ}$ and $16.7 \pm 13.5^{\circ}$, respectively. For the other substrates, it was slightly higher, ranging from $29.8 \pm 11.1^{\circ}$ for Achilles tendons up to $43.7 \pm 16.2^{\circ}$ for collagen films. The three-armed glue had similar contact angles to all the substrates, ranging from 43 $\pm 3.3^{\circ}$ for collagen films to $54.3 \pm 2.6^{\circ}$ for chamois leather.

The water content of the substrates was between $63.3 \pm 1.8 \mathrm{wt}$ $\%$ for Achilles tendon up to $77.5 \pm 1.5 \mathrm{wt} \%$ for muscle tissue (Fig. 3). The collagen content of the human Achilles tendon is reported to be approximately $90 \%$ of the dry mass (mostly type I collagen). If we assume similar compositions of animal and human tissues, then taking the experimentally determined water content of $63.3 \mathrm{wt} \%$, the collagen content would constitute for approximately $24 \%$ of the wet mass. The experimentally measured meniscus water content of $68.9 \pm 0.8 \mathrm{wt} \%$ is very close to values reported in literature, which are found to be approximately 72 wt\% for healthy human meniscus. ${ }^{[15]}$ The collagen content of meniscus tissue is approximately $22 \mathrm{wt} \%$, mostly type I and II. In muscle tissue, on the other hand, collagen constitutes only between 2 and $6 \%$ of the wet mass. ${ }^{[16]}$ Assuming that both chamois leather and collagen films consist of only collagen, their collagen contents are approximately $26 \%$ of their wet mass.

The SEM images of the surfaces of the substrates showed clear differences in their morphology (Fig. 4). Chamois leather had numerous exposed fibers at the surface. The surface of the collagen film on the other hand, was smooth. The structure of the surfaces of the living tissue was relatively smooth with visible fibers aligned parallel to the surface. Dermabond ${ }^{\circledR}$ and the three-armed block copolymeric glue formed a smooth film on

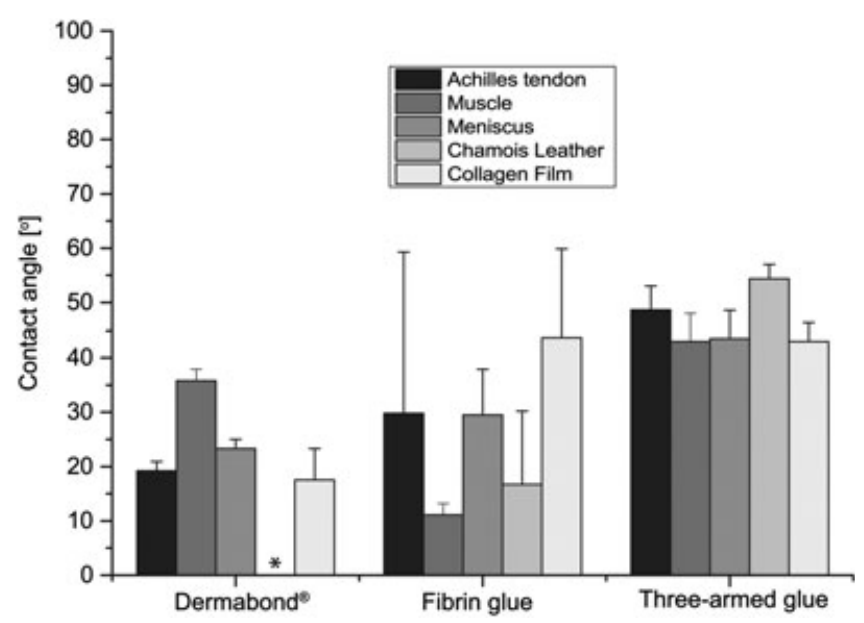

Figure 2. Static contact angles between glues and different hydrated substrates. Data are presented as mean \pm standard deviations. *Note that the contact angle between Dermabond ${ }^{\circledR}$ and chamois leather could not be determined because of immediate adsorption of the glue drop.

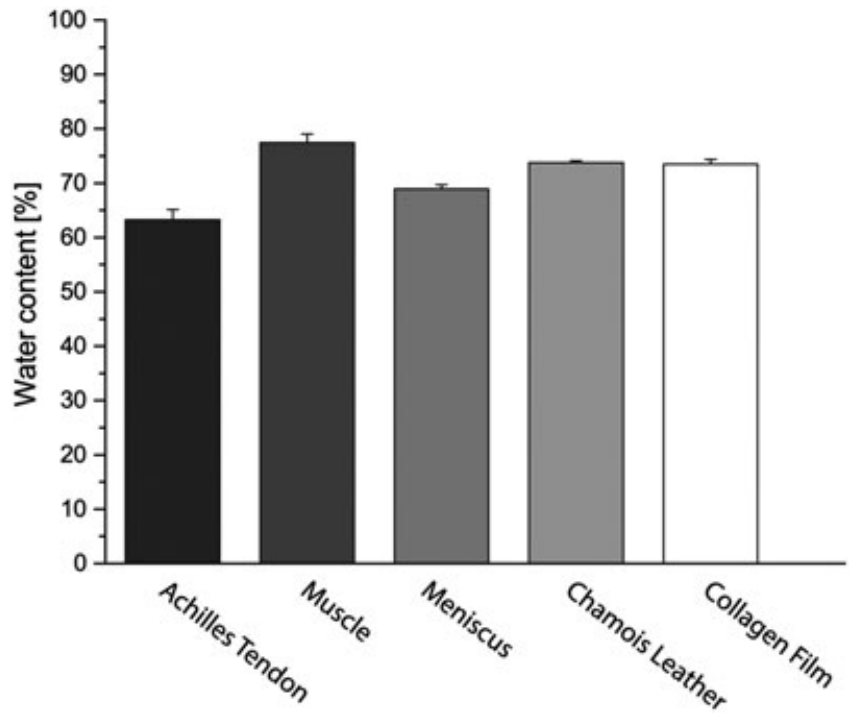

Figure 3. Water content of the investigated substrates. Data are presented as mean \pm standard deviations.

the surfaces of the substrates. Fibrin glue, on the other hand seemed to be partially absorbed by the substrates, which is especially pronounced on the chamois leather surface. This, however, might be the effect of the drying procedure of the samples.

Additionally, images of cross-sections of the chamois leather and meniscus specimens after application of the three-armed adhesive clearly showed that the glue had penetrated inbetween the fibers of the chamois leather (Fig. 5a). This was not the case with meniscus tissue, where the glue remained on the surface of the tissue (Fig. 5b).

\section{DISCUSSION}

In order to understand the differences in adhesive strength of particular glues to various substrates, the gluing process must be analyzed. The gluing process consist of three main steps: (i) spreading of the liquid glue on the tissue surface (wetting); (ii) attachment of the glue to the tissue; and (iii) curing of the glue (solidification). Steps (ii) and (iii) usually take place simultaneously. The attachment to the tissue can happen by means of chemical bonding, physical interactions (ionic interaction, van der Waals forces), or mechanical interlocking after solidification onto the surface of the substrate. ${ }^{[17]}$ Therefore, both the chemistry and adhesive mechanisms of the glues and factors such as chemical composition and hydrophilicity of the substrates and their surface morphology are critical in achieving adhesive bond.

Three tissue adhesives were evaluated in this study. A scheme of their chemical structure before and after curing is depicted in Fig. 6. Dermabond ${ }^{\circledR}$ is a 2-octyl cyanoacrylate; it polymerizes by reaction with trace amounts of water or upon contact with cell membranes and tissues ${ }^{[18]}$ (Fig. 6a). Fibrin glue is composed of fibrinogen and thrombin, and its curing mechanism resembles the final stages of blood coagulation when the two components are mixed together (Fig. 6b). It binds to the tissue by covalent bonding and the formation of hydrogen and electrostatic bonds. ${ }^{[19]}$ The three-armed isocyanate terminated copolymer we developed cures in the presence of water releasing carbon dioxide as a by-product, resulting in the formation of a solid 


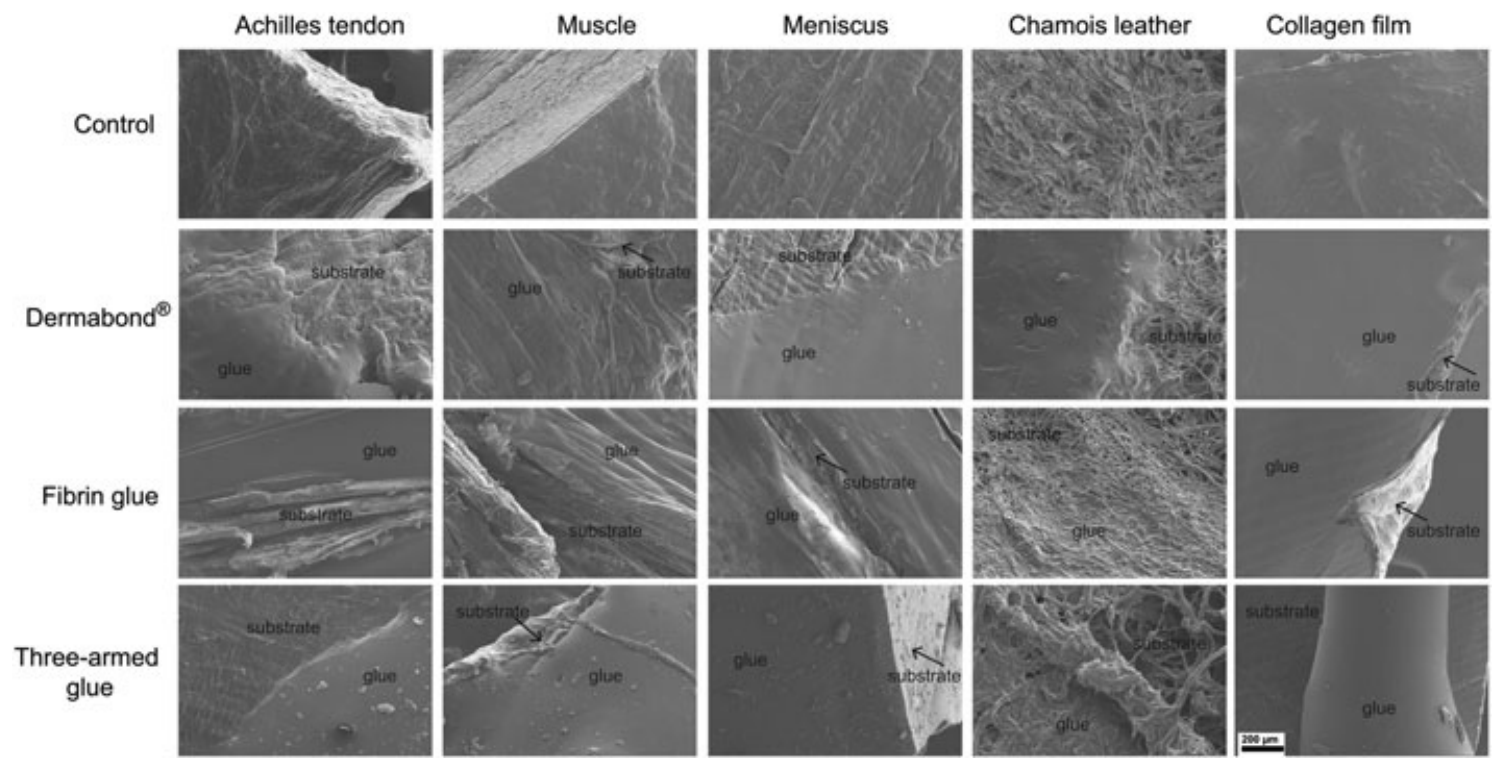

Figure 4. Scanning electron microscopy images of the top surfaces of the investigated biological substrates (top row), and the surfaces partially covered with the glues. The scale bar indicates $200 \mu \mathrm{m}$.
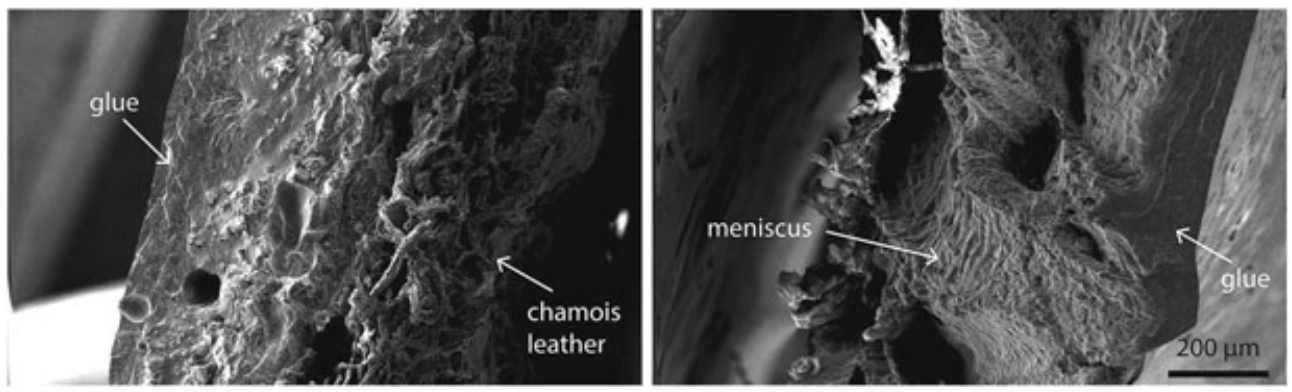

Figure 5. Scanning electron microscopy images of the cross-sections of chamois leather (left) and meniscus tissue (right) after application of the threearmed adhesive on their surface.

flexible polyurethane network (Fig. 6c). It attaches to the tissue via the formation of covalent bonds. ${ }^{[14]}$ All glues, additionally, attach by mechanical interlocking onto the surface of the substrate.

Contact angle measurement gives information of how well the glue can spread and wet the surface of the substrate. The lower the contact angle between the glue and the substrate, the better the wetting of the surface is and the higher the adhesive strength is to be expected.

Dermabond $^{\circledR}$ had similar contact angles to Achilles tendons, meniscus, and collagen films, and its adhesive strength to these substrates was high. The somewhat higher contact angle between Dermabond ${ }^{\circledR}$ and muscle tissue and the fact that the glue was absorbed immediately by chamois leather are probably the reasons for the lower adhesive strength to these substrates. Fibrin glue had various contact angles with the different substrates. Its (poor) adhesive properties did not show clear dependence on these values. Also, for the three-armed block copolymeric adhesive, no clear trend between adhesion strength and contact angle was established.

The collagen content and the hydrophilicity of the substrates are other factors determining the adhesive bond that can be achieved between glues and their surfaces. Muscle tissue had the lowest collagen content and the highest water percentage of all the substrates, and the adhesion strength of all three tested glues was relatively poor to muscle tissue when compared with other substrates. Moreover, both fibrin glue and the three-armed block copolymeric glue had higher adhesion strengths to chamois leather and collagen than to living tissues. It seems therefore, that the collagen content, which is higher for these two substrates than for the other substrates, is another critical factor determining the adhesion strength of these glues. Moreover, although the use of such synthetic substrates does not have the same clinical relevance as tests performed on living tissues, their production can be easily controlled thereby allowing to directly compare results obtained by different researchers. Furthermore, as their composition is well-defined, their use may increase the accuracy of the obtained adhesive results.

SEM images showed that chamois leather had numerous fibers exposed at the surface, possibly also allowing good mechanical interlocking of the glues. Indeed, the images of crosssections of chamois leather and meniscus tissue after application of the three-armed adhesive clearly showed that the glue had penetrated in-between the fibers of the chamois leather. This explains the much higher adhesive strength of the three-armed glue to chamois leather $(719 \pm 225 \mathrm{kPa})$ than to meniscus tissue $(88.2 \pm 50.8 \mathrm{kPa})$. In addition, except for Dermabond ${ }^{\circledR}$, which due to its low viscosity was immediately absorbed, also the fibrin glue had better adhesion to chamois leather than to the other 
a)

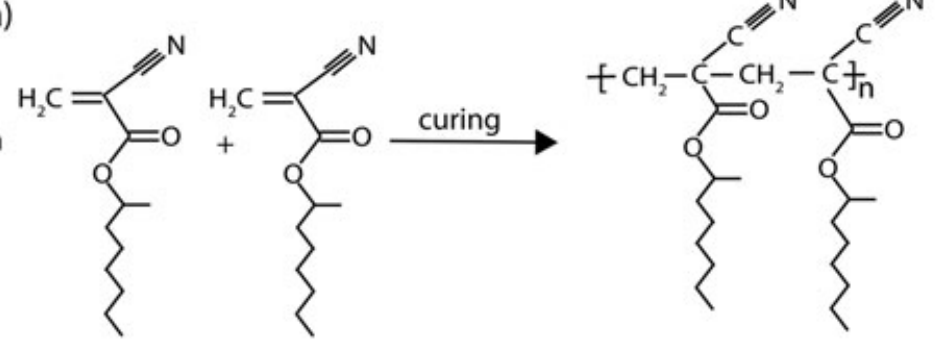

b)

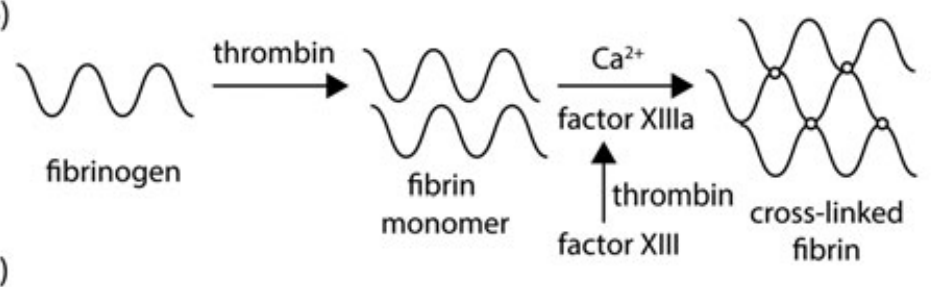

c)
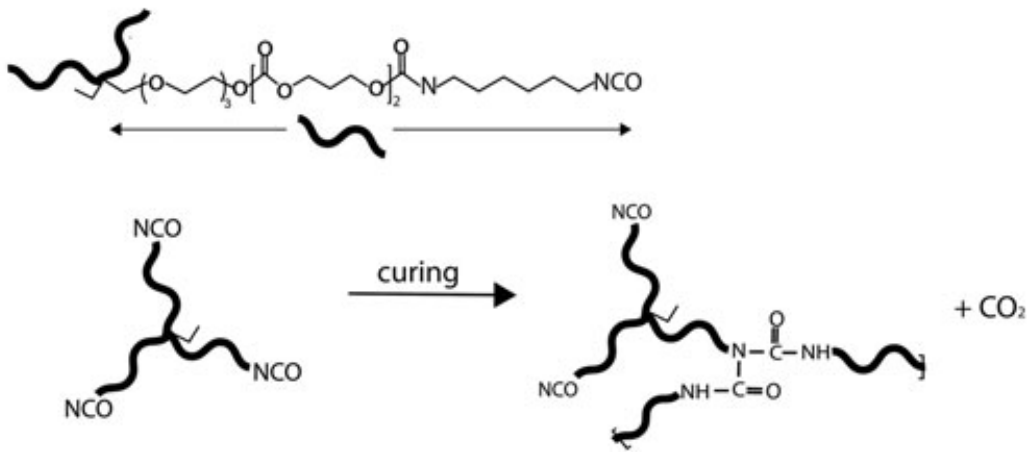

Figure 6. Scheme of the chemical structure of the used tissue adhesives before and after curing (adhesion), (a) Dermabond ${ }^{\circledR}$ (2-octyl cyanoacrylate) polymerizes through the contact with water or cell membrane, (b) fibrin glue, which is a mixture of fibrinogen and thrombin cross-links when these two components are mixed together, (c) the three-armed isocyanate-terminated adhesive copolymer polymerizes through the contact with water forming solid polyurethane network and releasing carbon dioxide as a by-product.

substrates. Furthermore, collagen films were a substrate that could readily be glued too by all three glues.

Based on the obtained results, it seems that collagen content, hydrophilicity, and surface topography are critical factors for achieving good adhesive bonds. Employment of substrates that mimic the natural living tissues of interest are the most promising materials with which to perform preliminary screening experiments in the development of novel adhesive materials. Nevertheless, in further evaluation of new materials, examination on the targeted animal or human tissues should be performed in a well-controlled and standardized manner.

\section{CONCLUSIONS}

The results of adhesion strength determinations showed that not only the glues but also the biological substrate had a significant influence on the adhesive strength of the bond. Therefore, there is a need for the development of unified tissue models and procedures to evaluate adhesive strengths in the development of novel tissue adhesives. Employing such a universal and standardized strategy would allow directly comparing the adhesive properties of different glues and extrapolating the results to the targeted human tissues.

\section{REFERENCES}

[1] L. Gross, R. Hoffman, Handbook of Adhesives. Van Nostrand Reinhold, New York, 1977.

[2] T. B. Bruns, J. M. Worthington, Am. Fam. Physician 2000, 61, 1383.

[3] W. D. Spotnitz, Am. J. Surg. 2001, 182, 8S.

[4] T. W. Gilbert, S. F. Badylak, E. J. Beckman, D. M. Clower, J. P. Rubin, J. Plast. Reconstr. Aesthet. Surg. 2013, 66, 414.

[5] J. A. Simson, I. A. Strehin, B. W. Allen, J. H. Elisseeff, Tissue Eng. Part A 2013, 19, 1843.

[6] J. Simson, J. Crist, I. Strehin, Q. Lu, J. H. Elisseeff, J. Orthop. Res. 2013, 31, 392.

[7] D. Cohn, G. Lando, Biomaterials 2004, 25, 5875.

[8] G. Lando, D. Cohn, J. Mater. Sci. Mater. Med. 2003, 14, 181.

[9] P. Ferreira, J. F. J. Coelho, M. H. Gil, Int. J. Pharm. 2008, 352, 172.

[10] P. Ferreira, A. F. M. Silva, M. I. Pinto, M. H. Gil, J. Mater. Sci. Mater. Med. 2008, 19, 111.

[11] T. Wang, J. Nie, D. Yang, Carbohydr. Polym. 2012, 90, 1428.

[12] B. H. Hu, P. B. Messersmith, Orthod. Craniofac. Res. 2005, 8, 145.

[13] N. Sheikh, H. Mirzadeh, A. A. Katbab, P. Salehian, M. Daliri, S. Amanpour, J. Biomater. Sci. Polym. Ed. 2001, 12, 707.

[14] A. I. Bochyńska, S. Sharifi, T. G. van Tienen, P. Buma, D. W. Grijpma, Macromol. Symp. 2013, 334, 40.

[15] J. Herwig, E. Egner, E. Buddecke, Ann. Rheum. Dis. 1984, 43, 635.

[16] Z. E. Sikorski, Chemical and Functional Properties of Food Proteins. CRC Press, Boca Raton, 2001.

[17] M. Mehdizadeh, J. Yang, Macromol. Biosci. 2013, 13, 271.

[18] B. J. T. Vote, M. J. Elder, Clin. Experiment. Ophthalmol. 2000, 28, 437.

[19] D. H. Sierra, J. Biomater. Appl. 1993, 7, 309. 